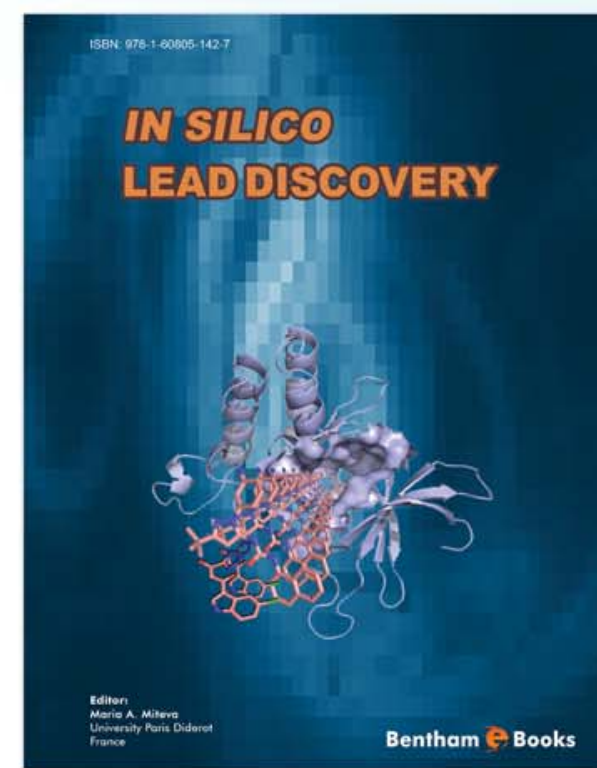

Editor:

Maria A. Miteva

France

\section{USS}

53.00

only

\title{
In Silico Lead Discovery
}

\section{WWW.Lenthamseience.com/ehooks/9781608051427}

\section{About the ebook}

In silico Lead Discovery is a compilation of the efforts of several experts on bioinformatics and drug design in developing the latest advances of in silico approaches for lead discovery. Biomedical scientists, biologists and chemists can find valuable information here that could help them to initiate or to complete chemical biology projects with the goal of designing new hit-tolead molecules or chemical probes.

\section{Contents}

Structure-Based Virtual Screening

3D Similarity Search for Lead Compound Identification

- Fragment-Based Methods for Lead Discovery

- Analyzing and Predicting Protein Binding Pockets

- Receptor Flexibility in Ligand Docking and Virtual Screening

- Application of In Silico Methods to Study ABC Transporters Involved in Multidrug Resistance

- Successful Applications of In Silico Approaches for Lead/Drug Discovery

For Sales Advertising Inquiries: Contact: marketing@benthamscience.org 